\title{
LA IDEOLOGÍA DEL JUEZ Y EL USO DE LA LEY COMO FUENTE DEL DERECHO
}

\section{THE IDEOLOGY OF THE JUDGE AND THE USE OF THE LAW AS A SOURCE OF LAW}

\section{TARIPIRINA AMUYT'AWI KAMACHI APNAQAWI KUNJAMA WAKISIRINA YATIYAWINAKAPA CH'IQIYIRI ${ }^{(1)}$}

\author{
Alex Garcés Medrano ${ }^{(2)}$ \\ Universidad Católica Lumen Gentium. Colombia
}

\begin{abstract}
Resumen: Este texto tiene como propósito dar cuenta de la problemática en torno al discurso jurídico, en tanto que los operadores jurídicos y particularmente el juez deben resolver las controversias jurídicas, permeadas por conflictos sociales, pero su insumo esencial son las fuentes del Derecho y particularmente la ley, lo que dificulta su posibilidad de comprender los diferentes fenómenos sociales que el Derecho como ordenamiento pretende intervenir. Adicionalmente, en ocasiones se incurre en dificultades de orden conceptual. Así, desde el enfoque de la Teoría Crítica, se propone que el supuesto de objetividad que tiene el juez, no es tal, porque en él subyace una carga ideológica. El juez, en sus decisiones, impone sus valoraciones y representaciones, su subjetividad: su ideología. Esto se demuestra en el campo probatorio, donde el juez escoge de acuerdo a su criterio qué pruebas y hechos corresponde con su discurso de la verdad.
\end{abstract}

Palabras claves: Ideología, Fuentes del Derecho, Teoría Crítica, Ciencias Sociales, Hermenéutica Jurídica.

Abstract: The purpose of this text is to account for the problems surrounding legal discourse, while legal operators and particularly the judge must resolve legal disputes, permeated by social conflicts, but its essential input is the sources

(1) Traduccion: Maria Teresa Goyzueta Zapata. Lengua Aymara

(2) Abogado, Politólogo, Magister en Filosofía del Derecho. Docente Universidad Católica Lumen Gentium. (Colombia), Doctorando Universidad Rey Juan Carlos. (España). E-mail: a.garcesm.2018@ alumnos.urjc.es 
of law and particularly the law, which makes it difficult for them to understand the different social phenomena that the Law as an order intends to intervene. Additionally, conceptual difficulties are sometimes incurred. Thus, from the Critical Theory approach, it is proposed that the judge's assumption of objectivity is not such, because an ideological charge underlies it. The judge, in his decisions, imposes his evaluations and representations, his subjectivity: his ideology. This is demonstrated in the evidentiary field, where the judge chooses according to his criteria what evidence and facts correspond to his discourse of truth.

Keywords: Ideology, Sources of Law, Critical Theory, Social Sciences, Legal Hermeneutics.

Aru takthapita: Aka aruchana utji amtawi ullachaña ch'axwa arst'awi juchanakata t'aqawi tuqita, kunakiti taripaña apnaqirinakaxa taripiri chikampi wakisiwa askichaña wali yatjatasa juchanaka t'aqaña jaqinakxata ch'axwanaka sarnaqawinakapasa taypita, ukaxa wakisirina aski yaanakapa kamachimpi nayriripuniñapa, ukasti ch'amampi jaritha yatthapiña kunaymana jaqinakxata chaxwanaka sarnaqawinakapasa utjaspa, kuna wakisirina arxataspa kunjama irjasa. Uka ch'amata layku juchanaka t'aqawi taypita pantjañanaka utjaspa. Ukhamaraki yati utjawi taypita yant'aña imantatanaka utjaspa ukata taripirisa jani wali t'aqañaru purispa, ukata taripirina amuyt'añapampi yant'anakasa wali ajllita chaninchañapa chiqpacha arst'awimpi jucha t'aqañapa.

Aski Aru: Amuyt'a, Wakisirina yatiyawinakapa ch'iqiyiri, amuyumpi yati utjawi, jaqinakxata yatjatawi, juchanaka t'aqaña tuqita kamachi yatjatasa. 


\section{Introducción}

En nuestro ejercicio docente del Derecho, nos hemos encontrado con una gran dificultad: la complejidad de la conceptualización. Porque el derecho como disciplina debe articularse con las ciencias sociales, y la red de conceptos que nos permiten analizar, comprender, interpretar y explicar la realidad social, es decir, las imbricaciones de tipologías teóricas como parte del conocimiento y los fenómenos que se dan al interior de las sociedades en el escenario de la globalidad. Esto implica que los docentes facilitemos al dicente el dialogo en torno a nociones, definiciones, conceptos, hipótesis y teorías que permitan unos niveles de reflexión críticos frente a las distintas situaciones que abarcan su objeto de conocimiento. En este caso los sistemas jurídicos.

Todos los días, nos vemos transversalmente afectados, por una cantidad de hechos y fenómenos sociales, que en la mayoría de las veces tienen un antecedente de carácter histórico, político, económico y social, y que, para poder ser comprendidos, requieren el insumo conceptual de las disciplinas que de una u otra manera han abordado dicho fenómeno. En este contexto, el acervo teórico de reflexiones que se ha producido a lo largo de la historia, nos permite abordarlo, para interiorizarlo con cierto nivel de reflexión epistemológica, y así -las más de las veces- poder dar cuenta del mismo, y en ocasiones, servir de insumo para transformar la realidad, por lo menos desde los discursos.

Pero lo anteriormente descrito, no siempre sucede, podemos negarnos ingenua o deliberadamente a pensar producto de un escenario de "la educación, tal como ella existe en la actualidad, reprime el pensamiento, transmite datos, conocimientos, saberes y resultados de procesos que otros pensaron, pero no enseña ni permite pensar" (Zuleta, 1995, p.19), o nos vemos inducidos a elaborar falsas concepciones de nosotros mismos (Morin, 1999) citando a Marx y Engels (Marx \& Engels, 1974).

Así, en vez de fortalecer la episteme, se incurre en la doxa, es decir en "una opinión o a un conjunto de opiniones, a veces también a una doctrina, que es aceptada acrítica y pasivamente por la tradición, por la costumbre o bien por una autoridad cuyo dictamen aceptamos sin discutirlo: "acríticamente" $y$ "pasivamente" (Bobbio, 1997, p. 184).

En este contexto, se terminan acuñando una serie de frases que cada vez toman más fuerza en el lenguaje cotidiano, como "separar el derecho de la política", "separar la ideología del derecho", "que las ideologías no existen" etc. Frases sin ningún tipo de revisión conceptual, con un nivel bastante superficial, y sin razón de ser. No se trata entonces, de un problema de insuficiencia de conocimiento, sino de llenura. 
La ignorancia no es un estado de carencia como se lo imagina el sentido común. Si fuese así, nada habría más fácil que la enseñanza que sería como dar de comer a un hambriento. Introducir algo allí donde hay una ausencia sería supremamente sencillo. Pero desgraciadamente la ignorancia no es un estado de carencia, no es una falta, sino -y esa es la fórmula de Platón- un estado de llenura; es un conjunto inmenso de opiniones en las que tenemos una confianza loca. La conciencia de saber que no se sabe es propia de la ciencia; no es en absoluto un atributo de la ideología (Zuleta, 2017, p.182).

De acuerdo a lo anterior, se trata de una de ignorancia que se va replicando en la cotidianidad, y se convierten en discursos bastante generalizados y formas de pensar, que se traducen en una sociedad llena de prejuicios, excluyente y violenta, porque no encuentra formas de argumentación para explicar sus posturas. Que en el caso colombiano hemos denominado de manera equivoca la polarización.

Por prejuicio se deben entender aquí aquellas interpretaciones que se aceptan por respeto a otros, como en el caso de las interpretaciones de la Biblia, o aquellas que se hacen de manera inmediata sin que medie ningún esfuerzo intelectual por parte del intérprete. A las primeras se les conoce como prejuicios por autoridad y a las segundas como prejuicios por precipitación (Herrera, 2009, p.129).

El lenguaje descrito, se convierte en un aparato ideológico, una especie de superestructura (Marx, 1859, p.2) que se inserta además de las formas de dialogo, en las de comprensión de los diferentes fenómenos y hechos, en este caso jurídicos que interesan a los actores de la comunidad jurídica. Así, es recurrente en el uso del lenguaje por parte de esta comunidad que ejercen como docentes, jueces, litigantes, servidores públicos, funcionarios de la rama judicial, gerentes de ONG, o entidades del sector privado, y estudiantes; el uso de un lenguaje del que no se sabe los alcances de las palabras que se están discutiendo, y permanentemente se incurre en el estiramiento conceptual (Sartori, 2011).

Esta situación al ser reiterada, se vuelve crónica, porque el ejercicio de pensar, se diluye en el creer. Creencias que luego resultan imposibles de contrarrestar en escenarios de dialogo y debate, así, "la fuerza del prejuicio depende generalmente del hecho de que creer como verdadera una opinión falsa corresponde a mis deseos, estimula mis pasiones, sirve a mis intereses" (Bobbio, 1997, p. 185), en síntesis, en una realidad falseada (Marx \& Engels, 1974). Es por esa razón que hemos orientado esta reflexión al ejercicio del juez, para tratar de describir como este fenómeno ha permeado los discursos que se traducen en ideología, con todas las consecuencias que trae consigo. 
Adicionalmente, describir cómo el insumo fundamental del juez como operador jurídico, son las fuentes del Derecho, lo cual restringe sus posibilidades de interpretación de la complejidad de la realidad circundante para él. Es decir, la limitación conceptual de las fuentes del Derecho para comprender los fenómenos sociales, limitan la comprensión de la realidad social; más si el Derecho reclama su estatus como disciplina, donde reduce su corpus, al ordenamiento jurídico y por tanto, al positivismo jurídico como ideología (Bobbio, 2001).

A priori, nuestra hipótesis es que las limitaciones que tiene el juez para comprender la realidad social que él interviene con sus decisiones, obedece el margen mínimo que le ofrece las fuentes del derecho, y particularmente la que más prevalece: la ley. Nuestro enfoque teórico, será la Teoría Crítica (Horkheimer, 2003). Nos referimos al juez, como operador jurídico, por ser uno de los sujetos de la cadena de actuaciones del quehacer jurídico que interfiere la vida de las personas, a través de sus sentencias, pero consideramos que este análisis es aplicable a cualquiera de los actores u operadores jurídicos, en cualquiera de los escenarios antes descritos, los estudiantes, inclusive.

Ese complejo entramado de jueces, funcionarios, abogados, notarios, etcétera, usa y utiliza el Derecho. Se puede decir que el dinamismo, la evolución y el ajuste del Derecho se deben a este tipo especial de personas que llamamos operadores jurídicos. La cambiante realidad social se ve recogida en el Derecho o favorecida e impulsada por él a través de su acción (Peces-Barba Martínez, 1986, p. 449).

\section{2. ¿Qué es la ideología y cómo afecta a la comunidad jurídica?}

En términos generales podemos afirmar que la ideología es denominada como un sistema filosófico que involucra, interesa y fundamenta las características del pensamiento sea de un sujeto, colectivo o contexto. En otros términos, se puede entender como un conjunto de elaboraciones sobre un contexto particular, que responde a los diferentes sistemas de la sociedad (jurídico, económico, político, social, cultural, moral, religioso), procurando la conservación, transformación o restauración en una práctica de la sociedad, en el caso que nos ocupa, la comunidad jurídica.

Adicionalmente, la ideología podemos concebirla como sistema que cuenta con cierta permanencia y estabilidad, y que fundamentan el vínculo social y está encaminada a la producción de representaciones que configuran las identidades individuales y colectivas, orientando su acción política. Dicho de otra forma, es una red de relaciones entre reglas -dotadas de cierta permanencia y estabilidad- que fundan el vínculo social y están orientadas a la producción de nociones, representaciones, formas de discurso, regímenes de acciones, pautas morales y procesos de asignación de identidad de sí (Baca Olamendi et al., 2000, p.323). 
En el caso del derecho se refleja en las reglas del sistema, que cuentan con una carga efectiva que definen las acciones y las significaciones, evidenciando un discurso y una cohesión que emerge en condiciones sociales y políticas, involucrando el sentido social de la acción individual y la experiencia social de los actores sociales.

Al respecto Marx y Engels (Marx \& Engels, 1974), hicieron énfasis en la condición real de la vida de los hombres, afirmando que sería manejada por la ideología y su condición alienante, e identificaron la ideología como el fenómeno óptico de la cámara oscura, la cual expone sus imágenes invertidas, dicha metáfora, representará la realidad trastocada que distorsiona a la voluntad, es decir la falsea. Desde esta perspectiva, el juez, cuenta con un insumo sustancial, para fundamentar sus decisiones: La ley; "con respecto a las fuentes del Derecho, la supremacía de la ley sobre las otras fuentes" (Bobbio, 2001, p.45). Esto implica, que debe ajustarse a un parámetro democrático, desde el punto de vista formal. Pero autoritario desde el punto de vista material, en razón a que dicha ley eventualmente puede corresponder a intereses, incluso, antidemocráticos e injustos.

De acuerdo a lo anterior, la ideología se convierte en una de las formas que las élites dominan y ejercen el poder, en todos los ámbitos de la vida social “Las ideas de la clase dominante son las ideas dominantes en cada época; o, dicho en otros términos, la clase que ejerce el poder material dominante en la sociedad es, al mismo tiempo, su poder espiritual dominante" (Marx \& Engels, 1974, p.50), más si se tiene en cuenta que en nuestro sistema democrático, el legislador es cuerpo colegiado que procura conciliar los intereses políticos de diferentes clases sociales. Al respecto, el profesor George Sabine refiriéndose al sistema democrático liberal, como antecedente para comprender el pensamiento de Marx dice:

El pensamiento político liberal, se desarrolló principalmente como elaboración de dos ideas sociales o morales fundamentales, que la política es, esencialmente, el arte de llegar a acuerdos no coactivos entre intereses antagónicos y que los procedimientos democráticos son el único camino efectivo para llegar a esos acuerdos (Sabine, 1998, p. 561).

De acuerdo a lo anterior, las democracias liberales, tienen como acuerdo procedimental la ley, es decir, como parámetro obligatorio de comportamiento social, pero indudablemente, esto se presenta desde el punto de vista formal, por tanto, en la práctica, se imponen los intereses de las élites que detentan el poder político, ya sea de forma directa o por interpuesta persona. Adicionalmente, hay que reconocer que Marx de manera dogmática no atinó en su tesis determinista en cuanto al declive de la democracia, a partir de su planteamiento de la "dictadura del proletariado", porque nunca sucedió. 
La otra cuestión, es que la democracia, así sea desde el punto de vista formal, es un escenario con unas reglas mínimas, que tiene la forma de auto reformarse, para "corregir" sus desafueros. Cosa que no sucedió con los socialismos reales de ciertos países, por ejemplo, el posterior a la Revolución Rusa de 1917, que por el contrario desembocó en un régimen totalitario, con extremas formas de abuso de poder. Al respecto Bobbio dice:

Quiero aclarar que la única manera de llegar a un entendimiento al hablar de democracia, en cuanto contrapuesta a todas las formas de gobierno autocrático, es considerarla como caracterizada por un conjunto de reglas (primarias o fundamentales) que establecen quién está autorizado para tomar las decisiones colectivas y mediante cuáles procedimientos (Bobbio, 1985, p.62).

De acuerdo a lo anterior, al margen de nuestras críticas a nuestro sistema democrático, es claro que procedimentalmente, si es un avance como sociedad después de la Revolución Francesa, el poder concertar unas reglas de juego previas, para el ejercicio del poder político. En otros términos, al margen de las críticas a nuestra democracia, es un sistema al que hay que corregirle y es nuestro sistema político real.

Demos un último ejemplo. Considerada como una entidad efectiva del mundo real, la democracia ha sido concebida-como un conjunto particular de instituciones y de prácticas políticas, un cierto cuerpo de doctrinas jurídicas, un orden económico y social, un sistema que asegura el logro de ciertos resultados deseables o un proceso singular para la adopción de decisiones colectivas obligatorias (Dahl, 2002, p.14).

Nos referimos a ello, porque la labor del juez, necesariamente se circunscribe al marco de la democracia, tanto que él debe someterse a las reglas de juego, materializadas en la ley, pero ese no es nuestro objeto de discusión, sino que al margen de nuestro sentido crítico respecto del uso de las fuentes por parte del juez, hasta ahora es el sistema político más razonable, para no incurrir en el estado de naturaleza (Hobbes, 1980).

\section{La ideología en el Derecho y su relación con las fuentes.}

Desde el punto de vista epistemológico, el Derecho tiene como objeto de estudio el sistema normativo (Peces-Barba et al., 2000), y como método de aproximación la hermenéutica (Gadamer, 1993). Dicho de otra manera, el objeto de estudio de la ciencia jurídica, son las fuentes del derecho y su método de aproximación la interpretación de las mismas. El sistema normativo, se traduce en las fuentes del derecho, es decir, la ley, la jurisprudencia, la doctrina y los principios generales del derecho; de dichas fuentes, las más recurrentes es la ley; lo cual se 
convierte en una variable única para el juez comprender y abordar la complejidad de situaciones y controversias que se presentan en la sociedad.

De acuerdo a lo anterior, el juez, cuenta con un insumo fundamental, para resolver las controversias sociales históricas, como el del indígena y su territorio, el afrodescendiente y la exclusión, la mujer y su marginación, el gay y la homofobia, el niño y su negación, el pobre y la aporofobia, el extranjero y la xenofobia; además de las combinaciones que se presentan entre ellas. Es decir, su discurso está totalmente desprovistos de las categorías de análisis para interpretar los fenómenos que pretende incidir.

Poco sabemos acerca de las diferencias y similitudes en las ideas/ saberes sobre los que sustentan su práctica los operadores de la ley, el Derecho y los derechos. En otros términos: poco sabemos sobre los propios actores; empero, sabemos que sus posiciones y prácticas frente al Derecho y los derechos importan respecto de la vigencia del Estado de Derecho (Ansolabehere, 2008, p.332).

Lo anterior nos induce a pensar, que el operador jurídico, para resolver las controversias descritas, requiere de la comprensión de lo social (Herrera, 2009); pero no se trata de llenar vacíos con contenidos académicos, sino ser reflexivos de nuestro entorno, por supuesto, a partir de los insumos que nos brindan las tipologías teóricas, para no pensar en el vacío conceptual, sin referentes, pero tampoco, quedarnos -en el caso del Derecho- en los límites conceptuales de la ley, sino, entendernos como realidad humana.

Comprender no es, entonces, primariamente algo temático o teórico; es más bien esa condición en la que siempre nos encontramos y en la cual el mundo tiene significado para nosotros. Por tanto, las cosas y las personas están, originariamente, ante nosotros por tener que ver con nuestro mundo, con ese "estar ocupados en algo" que es tan importante en el análisis heideggeriano, y no puede pensarse que, inicialmente, son "objetos" aislados que luego se relacionan (Herrera, 2009, p.122).

De acuerdo a lo anterior, esa es la situación problemática del Derecho, porque esta disciplina, es de poca la estructuración conceptual para explicar la realidad social. Es decir, su objeto de estudio, esencialmente se ocupa de los sistemas normativos (Bobbio, 1993) y aborda desde sus limitaciones, las diferentes categorías de análisis que le son consustanciales, como el Estado, la democracia, el poder político, los derechos humanos, etc., y una cantidad de conceptos que comienzan a estar al "otro lado" de los cánones del derecho, y más con la tendencia positivista que ha imperado en la época contemporánea en la comunidad académica de juristas, desde Kelsen hasta nuestros días. 
La comprensión del mundo social se vuelve así una cuestión restringido a la coherencia entre conceptos la validez o representatividad del método su consistencia con el marco teórico específico o la precisión y exactitud de los lenguajes con los que se describe y explica la realidad una cuestión puramente teórica separada del mundo que si quiere comprender (Herrera, 2009, p.33).

Lo anterior significa que, un acercamiento interpretativo del Derecho solamente desde el alcance conceptual de sus instituciones jurídicas, precisamente corresponde, con la comprensión restringida, expuesta por el profesor Darío (Herrera, 2009). Así, entre más logra el derecho su estatus como disciplina, desde la perspectiva positivista, que reconoce las normas jurídicas como aquellas que tienen el respaldo del Estado, y que se diferencia sustancialmente de valoraciones extra sistémicas como la justicia; entonces, se restringe la posibilidad de explorar otras categorías de análisis que le permitan al operador jurídico comprender la realidad social, que pretende transformar. En términos de Kelsen:

Para una teoría positivista consecuente consigo misma el derecho (o el Estado) sólo puede ser un orden coactivo aplicado a la conducta de los hombres y esto no comporta ningún juicio sobre el valor de dicho orden desde el punto de vista de la moral o de la justicia (Kelsen, 2009, p.155).

Con el límite propuesto por Kelsen, de forma proporcional el Derecho se queda corto para explicar los fenómenos sociales que él mismo interviene. Un ejemplo es que el Derecho se ocupa de los tipos penales de peculado y cohecho y su articulación con las normas procesales aplicables al caso; y no, de la comprensión de la corrupción como fenómeno social, en este último caso el Derecho y particularmente la comunidad de juristas, no tienen las categorías conceptuales para explicarlo. Por esa razón sus opiniones no van más allá de proponer formas jurídicas para resolver el asunto (Ansolabehere, 2008), las cuales, resultan siendo reiterativas y superficiales.

En la línea de lo mencionado anteriormente, es oportuno señalar la ideología opera como una herramienta de control sociopolítico, si el juez, tiene como único parámetro la ley del Estado. En este caso lo que hará es reproducir un discurso al que le será irrelevante la justicia. Adicionalmente, en el contexto del Derecho se puede señalar que la noción de ideología involucra una representación y una serie de acciones que proporcionan una perspectiva de la realidad articulada con un sistema de creencias, valores, ideales y juicios, que pretenden operar en un contexto determinado para tergiversar, manipular o dominar un fenómeno de la vida social.

Dicho lo anterior, podemos afirmar que el discurso jurídico en los diferentes niveles de la escalera de la abstracción (Sartori, 2011), desde los más bajos (los 
hechos), hasta los más altos (las teorías) debe procurar por "subir y bajar la escalera", es decir, que el juez debe procurar salir-conceptualmente hablando- de los límites que le establece la ley como fuente del derecho, de lo contrario, estará permeado por un referente ideológico, que eventualmente puede traducirse en contenidos vacíos y prejuiciosos.

En cambio, en otros casos, llegamos a altos niveles de abstracción mediante una escalada de abstracción. En ese caso tenemos que tratar con términos de observación, es decir, con términos obtenidos de cosas observables, o mejor dicho obtenidos mediante inferencias de abstracción que van a parar, de algún modo, a observaciones directas o indirectas (Sartori, 2011, p.16).

Lo anterior pone de presente que, por la dinámica social, el legislador siempre además de obrar con intereses de clase, siempre se quedará corto para regular las conductas de los destinatarios. Precisamente, esos vacíos son los que debe llenar el juez, subiendo la escalera de la abstracción. Es decir, procurando acudir a categorías conceptuales de análisis que le permitan ir más allá, de los límites interpretativos que le impone la ley como fuente de derecho.

En correspondencia con lo descrito anteriormente, Gadamer (1993) planteó un nuevo parámetro de interpretación jurídica, es decir un "giro hermenéutico", al establecer que el operador jurídico en su ejercicio se enfrenta a una especie de dialéctica entre la generalidad de la norma y la particularidad de los hechos. Inferimos que esta propuesta de interpretación sugiere el reconocimiento de las complejidades sociales que rodean los casos concretos, los cuales el juez, siempre contrasta.

En el lenguaje que yo he empleado, y que he justificado con mi propia investigación de la historia terminológica, esto significa que la aplicación es un momento de la comprensión misma. $Y$ si en este contexto pongo en el mismo nivel al historiador del derecho y al jurista práctico, esto no significa ignorar que el primero se ocupa de una tarea exclusivamente "contemplativa» y el segundo de una tarea exclusivamente práctica. Sin embargo, la aplicación existe en el quehacer de ambos. ¡Y cómo habría de ser distinta la comprensión del sentido jurídico de una ley en uno y otro! indudablemente el juez se plantea por ejemplo la tarea práctica de dictar una sentencia, en lo que pueden desempeñar algún papel consideraciones jurídico-políticas que no se plantearía un historiador del derecho frente a la misma ley. Sin embargo ¿hasta qué punto implicaría esto una diferencia en la comprensión jurídica de la ley? La decisión del juez, que «interviene prácticamente en la vida», pretende ser una aplicación correcta y no arbitraria de las leyes, esto es, tiene que reposar sobre una interpretación "correcta», y esto implica necesariamente que la comprensión misma medie entre la historia y el presente (Gadamer, 1993, p.4). 
Desde la perspectiva de Gadamer, el hecho de sugerir, que para el operador jurídico es importante considerar el antecedente histórico de su objeto de análisis, se infiere aspectos extrasistémico que van más allá de lo normativo. Por ejemplo, jurídicamente el tema de la propiedad como institución jurídica, tiene unos alcances establecidos en la ley, pero como fenómeno social está transversalmente afectada por hechos sociales como el conflicto, el abuso de poder, el desplazamiento forzado, la vulneración de derechos humanos, el desconocimiento de simbologías ancestrales, entre otros. Situaciones que el juez no debe desconocer, por lo menos al resolver los casos más complejos, es decir los caos difíciles (Dworkin, 1989).

\section{4. ¿Por qué se afirma que el juez tiene una ideología?}

La Teoría Crítica como enfoque teórico nos ayuda a dilucidar esta cuestión, sus orígenes se remontan a comienzos del siglo pasado en la Escuela de Frankfurt, e introdujo un paradigma que sirve para comprender el fenómeno social. Consistió en una obra reflexiva de varios académicos como Max Horkheimer, Herbert Marcuse, Theodor Adorno y Erich Fromm entre otros; este grupo, presidido por Max Horkheimer, en 1937 publica un texto denominado "Teoría Crítica y teoría tradicional", dando cuenta de dos extremos teóricos de la investigación social, que, según ellos, hasta ese momento se había fundamentado en el modelo positivista de las ciencias naturales, y había perdido de vista, el análisis de los hechos sociales, desde las percepciones reales.

Las ciencias del hombre y de la sociedad se esfuerzan por imitar el exitoso modelo de las ciencias naturales. La diferencia entre escuelas que en materia de ciencias sociales se orientan más hacia la investigación de hechos, o bien se concentran más en los principios, nada tiene que ver con el concepto de teoría como tal. En todas las especialidades que se ocupan de la vida social, la prolija tarea de recolección, la reunión de enormes cantidades de detalles sobre determinados problemas, las investigaciones empíricas realizadas mediante cuidadosas encuestas $u$ otros medios auxiliares, como las que, desde Spencer, llenan gran parte de las actividades universitarias, en especial en los países anglosajones, ofrecen, por cierto, una imagen que exteriormente parece más próxima a los otros aspectos de la vida, propios del modo de producción industrial, que la formulación de principios abstractos o que el examen de conceptos básicos en la mesa de trabajo, como fueron característicos de una parte de la sociología alemana (Horkheimer, 2003, p.225).

Sustancialmente los planteamientos, fueron, en primer lugar, que la teoría tradicional, había sido una forma de aproximarse y reproducir conocimiento útil, para reproducir una situación de desigualdades sociales, que en el contexto de Europa de comienzos de siglo XX ya había producido una Guerra Mundial, además 
de una situación de pobreza generalizada, eso implicaba que en 1920, cuando surge este grupo de académicos se vislumbraba, una nueva oleada de conflictos azuzados también por el resentimiento alemán por la pérdida de la Primera Guerra.

Una de las características de este paradigma, según Horkheimer y sus colegas, era que las ciencias sociales habían pretendido hacer una separación entre sujeto de investigación y objeto, conduciendo la aproximación del conocimiento por un sendero ideológico. "Pero en la medida en que el concepto de teoría es independizado, como si se lo pudiera fundamentar a partir de la esencia íntima del conocimiento, por ejemplo, o de alguna otra manera ahistórica, se transforma en una categoría cosificada, ideológica" (Horkheimer, 2003, p.229). En oposición a lo anterior, estos académicos, promovieron la teoría crítica, como una aproximación al conocimiento que no pretendía separar el sujeto cognoscente (el investigador) y el objeto conocido (el hecho social).

Para el caso que nos ocupa, según este enfoque, pretender una separación "objetiva" entre el juez y sus decisiones, es una ilusión. En razón a que él, se involucra a partir de su subjetividad, la cual es inescindible, por tanto, el operador jurídico, en sus sentencias, plasma su cosmovisión, convicciones, su historia, sus prejuicios; en síntesis: su ideología.

Por consiguiente, en términos reales no es posible la separación entre objeto conocido y sujeto cognoscente, y por tanto en conocimiento e interés, esto es entre investigador y objeto, es decir, se hace necesario el involucramiento entre la subjetividad del observador social y los hechos que le rodean, para develar los intereses que predomina en la difusión del conocimiento. Dado que la teoría tradicional impide hacerlo y por el contrario reproduce un discurso que ha contribuido a las injusticias sociales. Si bien es cierto, este planteamiento está más asociado a la teoría del conocimiento, desde nuestra perspectiva también es aplicable al juez, en razón a que no es ajeno a esta situación, más si sus decisiones afectan ostensiblemente la vida de las personas.

En el sentido de la discusión propuesta, es oportuno traer a colación, un debate recurrente al interior del discurso jurídico, y tiene que ver con el tema probatorio, el cual, en nuestro criterio, contribuye a reforzar nuestro argumento. En el sentido de que, se parte de la objetividad del juez en el ejercicio de valoración probatoria. Siendo que es precisamente eso, una "valoración", es decir en última instancia, el juez escogerá de acuerdo a su criterio cual prueba él considera más acertada. En este sentido, Sebastián Reyes Molina (Reyes, 2016) citando a Jerome Frank, uno de los realistas jurídicos norteamericanos más reconocidos, describe una situación que pone en evidencia los vacíos del sistema jurídico frente al asunto: 
Uno de esos problemas, que en tanto permanezca sin solución provocará dramas diarios, es el de obtener un conocimiento correcto de los hechos en la etapa probatoria de los pleitos judiciales. Cuando hace unos veinte años, un fiscal dijo, muy ufano, que los hombres inocentes nunca eran condenados como criminales, Borchard le replicó, en 1932, con la publicación de su gran libro Convicting the Innocent (...) donde reveló que muchos hombres fueron a la cárcel por delitos que no habían cometido, debido a que los tribunales de primera instancia (...) habían incurrido en errores en la apreciación de los hechos. Como tales errores se deben a defectos judiciales en la determinación de los hechos-defectos presentes tanto en litigios civiles como penales-, resulta que los hombres no solo pierden su libertad sino también a menudo su propiedad, ahorros, trabajo o reputación por causa de fallos fundados en el 'hallazgo' judicial de hechos que nunca han ocurrido realmente (Reyes, 2016, p.266).

Desde esta perspectiva, si la principal fuente del derecho es la ley, ella es producto de transacciones y negociaciones de los factores reales de poder (Lasalle, 1994). Cuando el juez la tiene que aplicar no hay lugar a deliberaciones, desde esta perspectiva lo hace mediado por un aparato ideológico que le impone un estándar, en ocasiones aparentemente democrático.

Otra forma de demostrar la subjetividad y por tanto la ideología del juez, son las reglas de la sana crítica, cuya noción tiene su origen en el derecho español de 1885, cuando estableció en el artículo 317 del Código Procesal Civil “Los jueces y tribunales apreciarán según las reglas de la sana crítica la fuerza probatoria de las declaraciones de los testigos". Institución jurídica que sería acogida en parte de Europa Continental e Iberoamérica, y que prevalece hasta nuestros días.

Desde la doctrina jurídica se ha procurado establecer cuáles son sus límites conceptuales (Vicente y Caravantes, 1856); (Couture, 1958); (Taruffo, 2013); entre otros, en el entendido de que su aplicación debe estar cargada de la racionalidad del juez, pero a pesar de eso no deja de ser una cuestión subjetiva, la cual supone que el sistema democrático ha decantado las instancias para que el profesional de derecho tenga la suficiente competencia intelectual y ética para garantizar su funcionamiento, pero eso no es óbice, para desconocer que la sana crítica en últimas contiene la carga subjetiva del juez. En este sentido una investigación empírica de Rodrigo Coloma Correa, al entrevistar a varios jueces sobre su concepción de la sana crítica, entre otras conclusiones dice:

Los jueces son proclives a describir el modelo de la SC desde su propia experiencia biográfica y no desde abstracciones. Esta individualización del discurso se infiere de cierta incomodidad para comunicar qué significa valorar la prueba según este modelo, más allá de la explicación mediada 
por los saberes expertos sobre la SC. Es esperable que la incomodidad provenga, por una parte, de la ausencia de un lenguaje dogmático que haga posible comunicar de manera estandarizada qué es lo que hace un juez cuando juzga un caso según el modelo en cuestión; y, por otra parte, de la imposibilidad de traducir la SC en una práctica judicial generalizada, estable y aceptada sobre la valoración de la prueba (Correa \& San Juan, 2014, p.405).

A pesar de que el origen de la institución jurídica tiene aproximadamente doscientos años, todavía se mantiene vigente las definiciones más clásicas de la sana crítica. Que, de buena fe, aluden a la razón, el discernimiento, la lógica, las reglas de la experiencia; pero todos los adjetivos y nociones, no logran dar cuenta del fin discursivo: la objetividad del juez.

Las reglas de la sana crítica son, ante todo, las reglas del correcto entendimiento humano. En ellas interfieren las reglas de la lógica, con las reglas de la experiencia del juez. Unas y otras contribuyen de igual manera a que el magistrado pueda analizar la prueba (ya sea de testigos, de peritos, de inspección judicial, de confesión en los casos en que no es lisa y Ilana) con arreglo a la sana razón y a un conocimiento experimental de las cosas (Couture, 1958, p.271).

Ahora bien, acoger la sana crítica como una institución del derecho procesal no es ninguna tragedia. Lo que se pretende es dar cuenta de que la decisión del juez, necesariamente está permeada por valoraciones subjetivas, es decir su ideología. Tal vez por ese motivo, las democracias contemporáneas, a través del derecho constitucional, han procurado establecer los límites institucionales, a través de garantías procesales, para efectos de educir el margen de arbitrariedad de los jueces, y concomitantemente, inducir al juez, a ser más razonable en la tensión que se presenta entre la aplicación del Derecho y la búsqueda de la justicia.

\section{Hacia un nuevo horizonte interpretativo.}

El derecho constitucional colombiano ha sufrido un cambio considerable en los últimos treinta años, la expedición de la Constitución Política de 1991 no se tradujo necesariamente en una situación de convivencia y de igualdades sociales, pero si estableció una serie de garantías para la persona humana, teóricamente pasamos del Estado de Derecho, al Estado Social de Derecho que tiene como eje sustancial la dignidad de la persona humana. Esta Constitución, recoge un acervo de acontecimientos históricos desde comienzos de Siglo XIX, como la Constitución de Weimar, el Tratado de Versalles, Los Derechos Humanos; es lo que Bobbio denominó el "giro hermenéutico". 
Con el tiempo, sin embargo, se hizo cada vez más evidente que la "ley" no podía responder por sí sola a esta expectativa, y que se requería de fuentes vivas, contextuales y dialógicas que, uniéndose a ella, la complementaran normativamente en casos de indeterminaciones, vacíos o contradicciones. El principio de legalidad tuvo que ensancharse para admitir la llegada del poder complementador e innovador de la jurisprudencia. Con esa innovación se ampliaba también la comprensión del ideal de "estado de derecho" (López Medina, 2015, p.15).

Eso ha implicado un rol del juez, al que tradicionalmente se había manejado en Colombia. Desde esta perspectiva, la jurisprudencia de la Corte Constitucional, comenzó a tener un protagonismo como fuente del derecho, entre otras razones, porque el juez constitucional -aún con su carga ideológica- visibilizó los derechos de la persona en Colombia. Así, el afrodescendiente, el indígena, la mujer, el joven, el niño, el anciano, el gay y eso que denominamos grupos históricamente vulnerables comenzaron a ser "nuevos" sujetos de derechos. ¿Cómo se ha hecho esto? A partir de que el juez constitucional ha integrado en la argumentación de sus sentencias, categorías de análisis adicionales al Derecho como disciplina. Pero todavía hay una tensión en la comunidad académica de juristas, y los grupos de poder, respecto de los alcances de las sentencias de la Corte.

Es cierto que los cambios se constatan fundamentalmente observando la misma realidad, pero si uno se instala en el espacio académico tradicional lo más probable es que no los advierta en toda su magnitud; pues es bastante evidente que en nuestras facultades de Derecho predomina, en general, una notable inercia que impide reconocer y asumir la nueva realidad, y así se sigue preparando a los futuros profesionales del derecho como si casi nada nuevo hubiese ocurrido en los últimos doscientos años (Vigo, 2017, p.173)

Para continuar con esta dinámica, de un juez que estructura sus fallos, teniendo en cuenta los sistémico y lo extrasistémico al derecho, no es suficiente una denominación retórica, es decir, no es suficiente reiterar que estamos en el marco de una sociedad democrática, a esto era lo que nos instaba Ortega y Gasset al decir "No es lícito ser ante todo demócrata, porque el plano a que la idea democrática se refiere no es un primer plano, no es un "ante todo'"' (Ortega Y Gasset, 2006, p.188). El maestro se refería a que para ser demócrata debía haber unos presupuestos éticos, lo mismo sucede con la labor del juez, por lo menos con los retos que impone las complejidades de la sociedad actual.

En el escenario descrito, las sociedades toman rumbos heterogéneos, en algunas hay desigualdad, escases, violencia, exclusión, deterioro ecológico, etc.; lo que implica que el desafío de transformación es grande. Pero desde el punto de 
vista real, unas sociedades propenden por maximizar el mayor nivel de bienestar a sus asociados, y otras recurren en una especie de círculo vicioso que les impide salir del estado en que se encuentran; el sistema jurídico no es ajeno a ello. Así, desde nuestros entornos, desde el reconocimiento y respeto del "otro", se imponen ciertos desafíos en la aproximación al Derecho, inclusive. Para procurar contribuir a revertir en términos reales, el deterioro social, para ello se requiere una especie de: Renacimiento, como retomar la llustración.

Según Gadamer, en la ilustración toma forma una distinción radical entre los prejuicios y la razón. El espíritu ilustrado nada por cierto aquello que recibe, todo lo contrario, sospecha de la tradición y quiere someter todo conocimiento del tribunal de la razón; pues sólo mediante este examen se garantiza que el conocimiento del mundo se ha resultado de una elección libre y autónoma, y no de una sumisión y reflexiva las interpretaciones vigentes. Así, el conocimiento correcto de las cosas se comprendió como algo distinto de los prejuicios, yéstos tomaron una connotación negativa que conservarán siglos después (Herrera, 2009, p.129).

\section{Conclusiones}

La Ilustración trajo consigo la consolidación del conocimiento y el reconocimiento de este como insumo para intentar explicar los distintitos fenómenos sociales. Desde entonces, se han presentado diversas discusiones epistemológicas que se reflejan en un acervo de reflexiones en torno al ser humano, y el plexo de situaciones que le rodean; esta cuestión en el contexto de las ciencias sociales, ha contribuido a comprender el quehacer humano. El derecho como una disciplina que tiene por objeto el estudio de las normas del Estado que regulan el comportamiento social, tiene una gran dificultad, en razón a que sus categorías de análisis tradicionales, restringen el campo de interpretación de los fenómenos que él mismo pretende intervenir.

Esta situación se traduce, en operadores jurídicos distantes para poder explicar y comprender las realidades sociales, que en ocasiones lo que hacen es reproducir discursos excluyentes y contenidos de prejuicio. Pero bajo el supuesto de operar en el marco de sistemas democráticos se da por sentado el cumplimiento de fines, entre otros, el de la justicia. Asumiendo que el juez, en su ejercicio, per se, procede con la objetividad que imponen las reglas, por consiguiente, él procede de manera neutral y antiséptica, sin involucrar su subjetividad en los problemas jurídicos que son de su competencia, es decir, sin extender su ideología en sus sentencias; pero la realidad da cuenta de un proceder de los sistemas judiciales que pugnan con los derechos de grupos históricamente marginados como los indígenas, afrodescendientes, gays, la mujer, los campesinos, etc. 
Desde la perspectiva de la teoría Crítica, esa pretensión del juez objetivo se desdibuja, y por el contrario pone de presente que, en ocasiones ha servido para mantener una situación de desigualdades sociales, por el contrario, contribuyendo a revitalizar conflictos históricamente no resueltos. El supuesto del juez sin ideología lo que ha servido es como un aparato ideológico del Estado, que ha sido útil a los intereses de ciertas clases privilegiadas. El argumento lo refuerzan las instituciones jurídicas del sistema probatorio, como la sana crítica, que a pesar de tener dos siglos de existencia, en síntesis, reconoce que el juez en últimas decide de acuerdo a las valoraciones subjetivas que él considere en un caso en particular.

A pesar de lo anterior, los sistemas democráticos han evidenciado esos errores y en el caso colombiano se ha notado un leve y concreto cambio frente a la problemática presentada, se ha visto un avance sustancial jalonado por la Corte Constitucional, para tratar de corregir este asunto, como mencionamos anteriormente, después de la Constitución Política de 1991 y la reconfiguración del Estado, entre otras, estableciendo un órgano judicial de cierre y sus sentencias, comenzaron a resquebrajar una tradición en el manejo de esta fuente y de aproximación al derecho, que era conservadora, decimonónica y excluyente, por lo menos en la forma que se asumía la jurisprudencia como fuente del Derecho.

Alaalturadel año 2001, pues, lassentencias dela Corte Constitucional estaban acabando de construir una doctrina del precedente judicial a la colombiana, basada especialmente en el principio de igualdad del artículo 13 de la C.P12. El punto final de esta construcción se dio en la sentencia C-836/01: en ella se hacía una elaboración y síntesis completa de la doctrina del precedente judicial tal y como la había delineado la Corte en los años anteriores; $y$, al mismo tiempo, se terminó de alinear los textos legales (en este caso el sempiterno artículo $4^{\circ}$ de la Ley 169 de 189613) a favor de su implementación decidida (López Medina, 2015).

La tradición nuestra era la de un Estado premoderno que, en su Constitución Política de 1886, recientemente modificada, reconocía la ciudadanía sólo al hombre, blanco, católico, con patrimonio, que sabía leer y escribir; es decir, sintetizaba todas las exclusiones en pocas variables. La lectura de los jueces a la jurisprudencia como fuente del Derecho, era de "Las citas jurisprudenciales usuales buscaban ilustrar la elaboración conceptual de las instituciones jurídicas, exigiendo así coherencia conceptual, pero no necesariamente decisional entre los casos" (López Medina, 2015, p.16). Eso en la actualidad ha cambiado sustancialmente.

La manera en que el Derecho contemporáneo tal vez, pueda enfrentar los desafíos que le imponen un sistema social desigualitario y excluyente, es que los operadores jurídicos asumamos posturas subiendo y bajando la "escala de la abstracción" (Sartori, 2011), para poder visibilizar "nuevos" grupos que 
históricamente siempre han estado ahí; como indígenas, negros, mujeres, desplazados, comunidad LGTBI, etnias, jóvenes, niños, etc. Los operadores jurídicos y esencialmente el juez, debemos reflexionar desde los insumos de unas ciencias sociales pensadas en lo humano. Sólo así, se podrá lograr un juez que reconoce su ideología, pero procura un nivel de fundamentación en la razón.

La más evidente expresión de la concepción de diálogo, tal como lo desarrolla la filosofía hermenéutica, es la propuesta intercultural que hace Santos y que él denomina "hermenéutica diatópica" según Santos, como ya hemos visto, el horizonte hace posible que podamos comprendernos siendo diferentes tiene dos bases; por un lado, asumir que las necesidades humanas no son tan distintas de una cultura a otra aunque los satisfactores sí lo sean; por otro, reconocer que toda cultura posee valor en sí misma, lo que significa que a cada una se le reconoce dignidad para participar en la conversación (Herrera, 2009, p.174)

La otra alternativa es unos operadores jurídicos sometidos a los aparatos represivos del Estado, porque funcionan con violencia y los aparatos ideológicos del Estado (Althusser, 1974), siendo este ultimo los números de realidades que se presentan al observador inmediato bajo la forma de instituciones distintas y especializadas, situación que se puede manifestar en todos los niveles de la vida social.

Lo que se traduciría que en ambos aparatos estarían presididos por la clase dominante, todos funcionando con base a la represión y su articulación con la ideología, con la diferencia que el aparato represivo del Estado funciona en forma masiva prioritaria con base en la represión, mientras que los aparatos ideológicos del Estado funcionan en forma masivamente prioritaria con base en la ideología.

\section{Bibliografía}

ALTHUSSER, L. (1974). Los aparatos ideológicos del Estado (2.a ed.). Oveja negra.

ANSOLABEHERE, K. (2008). Legalistas, legalistas moderados y garantistas moderados: Ideología legal de maestros, jueces, abogados, ministerios públicos y diputados. Revista mexicana de sociología, 70(2), 331-359.

BACA OLAMENDI, L., Bokser-Liwerant, J., Castañeda, F., Cisneros, I. H., \& Pérez Fernández Del Castillo, G. (2000). Léxico de la política (1.a ed.). Facultad Latinoamericana de Ciencias Sociales, Sede Académica de México.

BOBBIO, N. (1985). El futuro de la democracia. Estudios Políticos, 4(1), 62-73. http:// dx.doi.org/10.22201/fcpys.24484903e.1985.1.60131

BOBBIO, N. (1993). Teoría general del Derecho (1.a ed.). Debate. 
BOBBIO, N. (1997). La naturaleza del prejuicio. Racismo, hoy. Iguales y diferentes. En Elogio de la templanza y otros escritos morales (pp. 183-197). Ediciones temas de hoy S.A.

BOBBIO, N. (2001). El problema del positivismo jurídico (7.a ed.). Fontamara.

CORREA, R. C., \& San Juan, C. A. (2014). Fragmentos de un Imaginario Judicial de la Sana Crítica. FRAGMENTS OF A JUDICIAL IMAGINARY ABOUT SOUND CRITICISM., 20(2), 375-413. https://doi.org/10.4067/S0718-00122014000200011

COUTURE. (1958). Fundamentos de derecho procesal civil (3.a ed.). Roque Depalma Editor.

DAHL, R. (2002). La democracia y sus críticos. Paidos.

DWORKIN, R. (1989). Los derechos en serio (2.a ed.). Ariel.

GADAMER, H.-G. (1993). Verdad y método (5.a ed.). Ediciones Sígueme.

HERRERA, J. D. (2009). La comprensión de lo social (1.a ed.). CINDEFundación Centro Internacional de Educación y Desarrollo Humano.

HOBBES, T. (1980). El leviatán (2.a ed.). Editora Nacional.

HORKHEIMER, M. (2003). Teoría tradicional y teoría crítica (1.a ed.). Amorrortu.

KELSEN, H. (2009). Teoría pura del derecho (4.a ed.). Eudeba.

LASALLE, F. (1994). ¿Qué es una constitución? (2.a ed.). Panamericana.

LÓPEZ MEDINA, D. (2015). Obediencia judicial y administrativa de los precedentes de las Altas Cortes en Colombia: Dos concepciones del fin y uso de la jurisprudencia como fuente del derecho. Precedente. Revista Jurídica, 7, 9-42. https://doi. org/10.18046/prec.v7.2202

MARX, K. (1859). Prólogo a la contribución a la crítica de la economía política. https://www.marxists.org/espanol/m-e/1850s/criteconpol.htm

MARX, K., \& ENGELS, F. (1974). La ideología alemana. Grijalbo.

MORIN, E. (1999). Los siete saberes necesarios para la educación del futuro. Santillana.

ORTEGA Y GASSET, J. (2006). Democracia Morbosa. Humanitas (07172168), 41, 187189.

PECES-BARBA, G., Fernandez, E., \& De Asis, R. (2000). Curso de teoría del derecho (2.a ed.). Marcial Pons Ediciones jurídicas y sociales S.A. 
PECES-BARBA Martínez, G. (1986). Los operadores jurídicos. Revista de la Facultad de Derecho de la Universidad Complutense, 72, 447-469.

REYES, S. (2016). Jerome Frank: Realismo jurídico estadounidense y los hechos en el derecho. EUNOMÍA. Revista en Cultura de la Legalidad, 265-293.

SABINE, G. H. (1998). Historia de la teoría política (3.a ed.). Fondo de Cultura Económica.

SARTORI, G. (2011). Cómo hacer ciencia política. Lógica, método y lenguaje en las ciencias sociales. Taurus.

TARUFFO, M. (2013). Verdad, prueba y motivación en la decisión sobre los hechos (Vol. 20). Cuadernos de Divulgación de la Justicia Electoral.

VICENTE Y CARAVANTES, J. de. (1856). Tratado histórico, crítico filosófico de los procedimientos judiciales en materia civil, según la nueva Ley de Enjuiciamiento, con sus correspondientes formularios. Imprenta de Gaspar y Roig.

VIGO, R. (2017). La interpretación (argumentación) jurídica en el Estado de Derecho Constitucional (1.a ed.). Tirant lo blanch.

ZULETA, E. (1995). Educación y democracia un campo de combate (2.a ed.). Corporación Tercer Milenio.

ZULETA, E. (2017). El elogio de la dificultad y otros ensayos (1.a ed.). Biblioteca Nacional de Colombia. 